\title{
Influence of Stem-cell Size and Culture Media Flowing Modality on Cell's Fate within a Microchannel; a Numerical Analysis
}

\author{
Daver Ali ${ }^{\text {(D) }}$ \\ Karabuk University, Department of Medical Engineering, Karabuk, Turkey
}

\section{A BS T RACT}

$\mathrm{T}$ The dynamic cell culture process has been widely used in tissue engineering. The success of cell culture is influenced by many factors, one of which is how the cells are transferred from the bioreactor to the scaffolds through microchannels. The risk that can reduce the success of the cell culture process is that the cells do not reach the final destination correctly. In this study, the movement of stem cells through a microchannel was theoretically analysed using discrete phase computational fluid dynamics. Three factors of cell size, fluid flow rate and fluid viscosity were investigated on their sedimentation rate before reaching the microchannel outlet. Four sizes of 10, 15, 20 and $30 \mu \mathrm{m}$ for cells, and four flow rates of 20,50, 90 and $180 \mu 1 / \mathrm{min}$ in addition, four viscosities of $0.001,0.005$, 0.01 and 0.025 Pa.s were selected for culture media left us a total number of 64 models. The analysis results showed that cells with smaller sizes have a better chance of reaching the microchannel outlet, and larger cells are more likely to sediment. On the other hand, higher flow velocities and higher fluid viscosity delivering more cells to the destination. The results of this study shed more light on the regulation and control of dynamic cell culture parameters.

\section{Keywords:}

Microchannel; Cell culture; Stem-cells; DPM Aanalysis; CFD analysis

\author{
Article History: \\ Received: 2021/05/26 \\ Accepted: 2021/09/15 \\ Online: $2021 / 09 / 29$ \\ Correspondence to: Daver Ali, \\ Karabuk University, Medical Engineering, \\ Karabuk, TURKEY \\ E-Mail: daverali@karabuk.edu.trPhone. \\ $+903704187021$
}

\section{INTRODUCTION}

A microfluidic device is a small scale channel that can be exploited in very fine fluid flow volumes. Nowadays, microfluidic systems gain more attention because of their increasing applications in many areas like computers' cooling systems [1], biological labon-chips [2], microparticles trapping in air purification [3]. Based on their application, these systems are prepared and used in very different dimensions and geometries. For example, in a microchannel that is used for heat transfer, increasing the wall surface area can increase its efficiency [4], wherein for a microchannel designed for cell tracking or trapping, applied forces on suspended cells are the determining factors that are highly dependent on fluid flow modality [5]. Therefore, based on the microfluidic system applications, very different parameters are considered in their design.

Although small-scale chemistry studies and physics analysis initially influenced microfluidic research, recently, the integration of cell biology with mic- rofluidics has become a significant focus of the scientific community [6]. In biological lab-on-chip systems, microchannels are used as a transporter of suspension from a reservoir to the final destination [7]. Before embarking on research involving complex biological systems containing live cells, the study of various aspects of fluid flow within microscale channels is inevitable. Many studies showed that conventional fluid dynamics theories are generally applicable in microchannels fluid flow analysis $[8,9]$. However, due to the small size of the microchannel, parameters such as surface roughness and wettability of their walls can cause differences in the way fluid flows in larger-scale channels [10-12]. Another factor that can add to studying fluid flow in microchannels, especially in biological systems, is the inherent complexity of biological fluids. For example, in terms of viscosity, most biofluids are non-Newtonian fluids $[13$ 14]. The problem is exacerbated when the microchannel operates in a system such as a cell culture where wall shear stress is a critical parameter to the success of the process [15]. Here the contradictory situation and the 
difficulty is that a high flow rate increases the wall shear stress at the destination, such as scaffolds walls [16, 17], and a low flow rate can cause microparticles and cells to deposit on the microchannel wall and finally its obstruction $[18,19]$. Therefore, finding an optimal flow rate considering the fluid properties and a suspended biological organism's physical aspects like its density and size is still a challenge for researchers.

In a dynamic cell culture system, cells are sent from a bioreactor to a destination, usually a synthetic scaffold. In such a system, microchannels are playing as transporters [20-23]. As with other microchannel systems, in dynamic cell culture, cell deposition can lead to process failure. Factors such as cell clogging [7], van der Waals forces [24], gravity or inertial forces [25] can cause the cells to settle before reaching the destination. Minimizing cell deposition within microchannels needs to control each causative factor sophisticatedly.

In addition to in-vitro studies, in silico simulations in the study of human cells have recently been considered [26-30]. For example, Marin et al. showed experimental and computational that a low flow rate in cell culture can cause cells to sediment in microchannels before reaching the outlet area [31]. In addition, a recent study by the author has performed a discrete phase model to probe the effect of scaffold architecture on the initial attachment of dynamic culture cells [32]. Natu et al. conducted a numerical analysis to examine stem cell movement in a cell sorting microchannel [33]. In a similar work Sun et al. performed a numerical simulation to predict the rare tumor cells movement inside a double spiral microchannel [34]. As can be seen in cell culture studies, computer simulations can provide reliable results, especially cell movement in microchannels.

In dynamic cell culture, the effect of the physical properties of the media can be very significant in process outcomes. For example, Torres et al. showed that adding macromolecules like dextran and Ficoll (Ficoll-Pq) could regulate media viscosity and density in controlling the rate of cell settlement on scaffolds [35]. Another factor affecting cell movement within a microchannel is its physical properties, including size, shape, and density relative to the fluid. Ge et al. showed that stem cells have an almost spherical geometry that varies in diameter from 10 to 35 microns [36]. However, to the author's best knowledge, no study in the literature examines the effects of all these parameters together. To address such a gap in the literature, in this study, the effect of flow rate, cell culture media properties, and the

Table 1. Fluid density and viscosity for CFD analysis.

\begin{tabular}{ccccc}
\hline Density $\left(\mathrm{kg} / \mathrm{m}^{3}\right)$ & 1000 & 1020 & 1022 & 1024 \\
Dynamic Viscosity (Pa.s) & 0.001 & 0.005 & 0.01 & 0.025 \\
\hline
\end{tabular}

size of the buoyant cells on their sedimentation rate within a fixed size microchannel were investigated theoretically.

\section{MATERIALS AND METHODS}

\section{Microchannel}

As mentioned in the introduction, the effect of fluid physical characteristics and cell size on their passage or settling was investigated in this study. A microchannel with a rectangular cross-sectional area of $3000 \times 1000 \mu \mathrm{m}$ and a length of $40 \mathrm{~mm}$ [31] was designed. The microchannel was used horizontally to take into account the effect of gravitational force on cells.

\section{CFD Analysis}

In this study, the cell culture media was considered a Newtonian and non-compressible fluid, and its flow was considered to be fully developed. Then the Navier-Stokes equation was used in CFD calculations [37]:

$$
\rho \frac{\partial u}{\partial t}-\mu \nabla^{2} \mathrm{u}+\rho(\mathrm{u} . \nabla) \mathrm{u}+\nabla \mathrm{p}=\mathrm{F}, \quad \nabla . \mathrm{u}=0
$$

where, $\mathrm{u}$, and $\mu$ represent the density $\left(\mathrm{kg} / \mathrm{m}^{3}\right)$, velocity $(\mathrm{m} / \mathrm{s})$, and the dynamic viscosity of fluid $(\mathrm{kg} / \mathrm{m} . \mathrm{s}) . \nabla$ denotes the del operator, and $\mathrm{p}$ denotes the pressure $(\mathrm{Pa})$. $F$ represents the forces, such as gravity and centrifugal force $[37,38]$. A No-slip boundary condition was assigned on the microchannel wall [39].

\section{Fluid Properties and Boundary Conditions in CFD}

Based on Torres et al. study result [35], four different densities and related viscosity were assigned to the culture media.

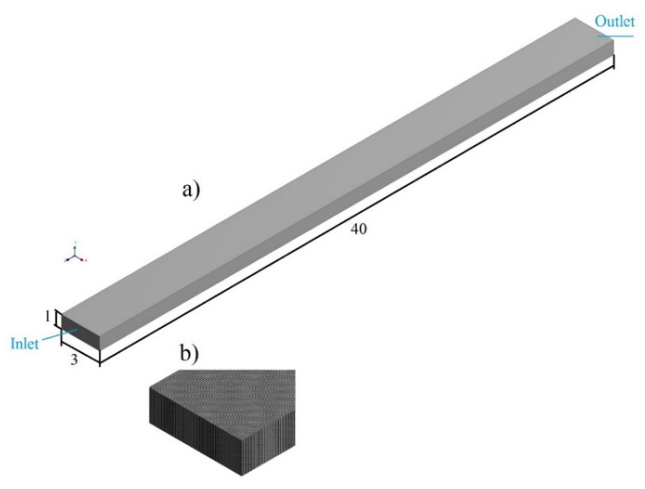

c)

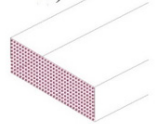

Figure 1. The microchannel model used in this study; a) geometry, b) mesh of the CFD analysis, c) cells injection from the inlet surface. 


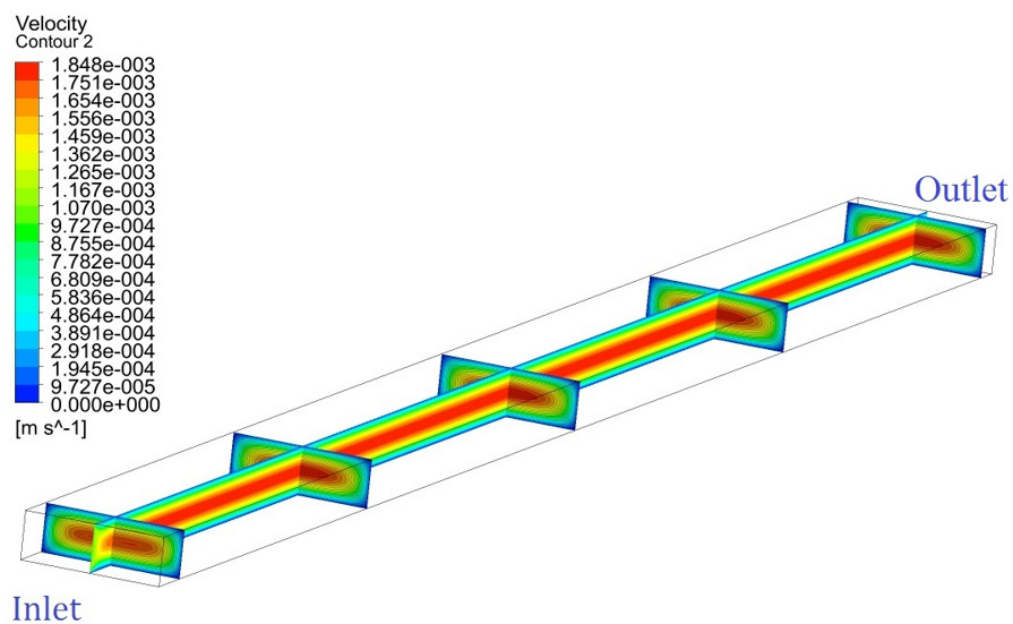

Figure 2. Velocity contour for the model with a flow rate of $180 \mu \mathrm{L} / \mathrm{min}$ and media viscosity of 0.005 Pa.s viscosity.

Also, four different inlet flow rates of 20, 50, 90 and 180 $\mu \mathrm{l} / \mathrm{min}$ were selected to investigate the effect of fluid velocity on the fate of cells within the microchannel [31]. The microchannel geometry was meshed using hexagonal elements with a size of $50 \mu \mathrm{m}$ and a total number of 960,000 elements (Fig. 1). For CFD analysis, the criterion of residual sensitivity was set as $1 \mathrm{e}^{-6}$.

\section{Governing Equations in Discrete Phase}

Cells motions within microchannels could be explained using particle motion equation[40], which was defined by the following equations:

$$
\frac{d U_{p}}{d t}=\mathrm{F}_{d}\left(U-U_{p}\right)+\frac{g\left(\rho_{\mathrm{p}}-\rho\right)}{\rho_{p}}
$$

and;

$$
\mathrm{F}_{d}=\frac{18 \mu}{\rho_{p} d_{P}^{4}} \frac{C_{p} \cdot R e}{24}
$$

wherein; $U_{p}, \mathrm{~F}_{d}, U, g, \rho_{p} \rho, \mu, d_{p^{\prime}} C_{d^{\prime}}$ and Re represented particle velocity $(\mathrm{m} / \mathrm{s})$, drag force $(\mathrm{N})$, fluid phase velocity $(\mathrm{m} / \mathrm{s})$, gravitational acceleration $\left(9.81 \mathrm{~m} / \mathrm{s}^{2}\right)$, cell density, fluid density, fluid dynamic viscosity, cell diameter, and an empirical drag coefficient factor for spherically-shaped particles [41]; respectively. Stem-cells were assumed as spheroids with 10,15, 20 and $30 \mu \mathrm{m}$ diameters in four sizes [36] as well as they were also modelled as a discrete phase with a density of $1130 \mathrm{~kg} / \mathrm{m}^{3}$ [27]. Moreover, oneway coupling was considered between cells and media so that only the fluid phase could affect the cells [31]. Three hundred cells were injected using the group injection method from the inlet surface with a zero velocity. This study assumed that the cells adhered to the microchannel walls had once collided with them. To this end, the trap condition was assigned to the interaction type between cells and microchannel walls [27].

\section{RESULTS}

Selecting four sizes for the cells' diameter and four different viscosities plus four flow rates for each model left a total of 64 models in this study. A small Reynolds number for all models ensures that the analysis is performed under a laminar flow (among all the models, the maximum $\operatorname{Re}=1.54$ ). Fig. 2 shows fluid flow conditions within the microchannel.

As can be seen, just after the inlet, the flowing fluid maintains its uniform flow contour to the end of the microchannel, indicating a fully developed flow, which was the same in all the models in this study. The streamlines of cells for four different models are shown in Figure to illustrate their fate.

As can be seen, except for the model with $10 \mu \mathrm{m}$ cell size, in all other models, all the injected cells have settled, and none of them has found a way outlet, indicating a determining role of cell size in how they move along the microchannel.

Fig. 4 shows the percentage of cells that settled before leaving the microchannel for each model.

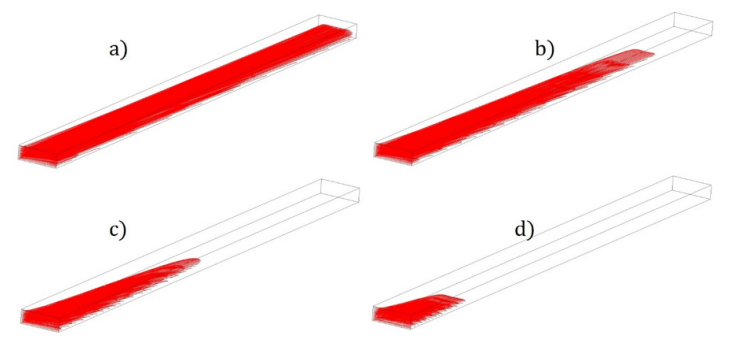

Figure 3. The path of the cell from the microchannel inlet for models with a flow rate of $90 \mu \mathrm{l} / \mathrm{min}$ and a viscosity of $0.005 \mathrm{~Pa} . \mathrm{s}$ and cell size a) $10 \mu \mathrm{m}$, b) $15 \mu \mathrm{m}$, c) $20 \mu \mathrm{m}$ and d) $30 \mu \mathrm{m}$. 
a)

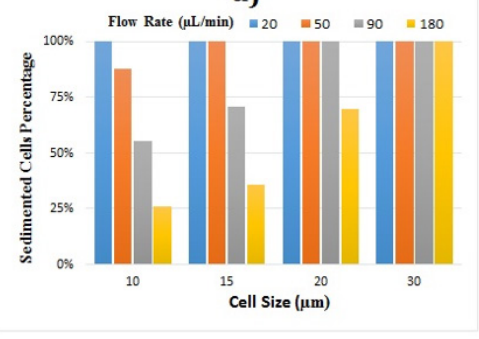

c)

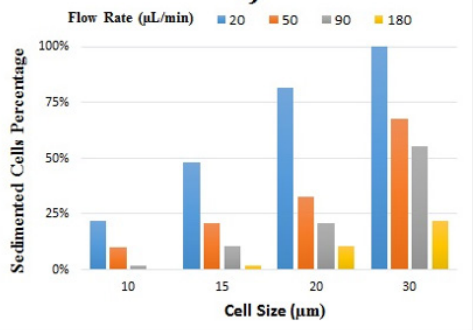

b)

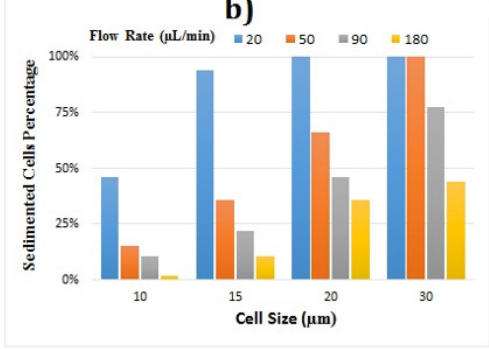

d)

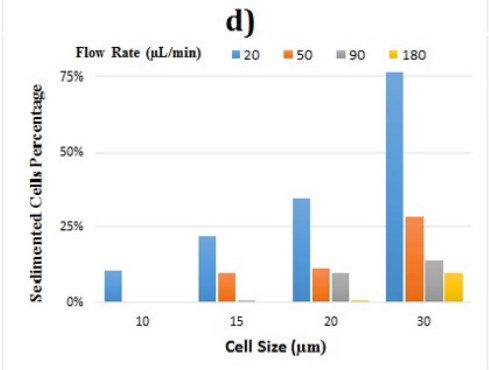

Figure 4. The number of sedimented cells was normalized with the total number of injected cells, and the assigned viscosity for the models' media was: a) 0.001 , b) 0.005 , c) 0.01 , and d) 0.025 Pa.s, respectively.

As shown in Fig. 4, all three parameters, namely cell size, viscosity and flow rate, were influential in the rate of cell deposition. In all models, the sedimentation rate increases with increasing cell size. However, increasing the flow rate and viscosity in the models has reduced cell sedimentation. Under a flow rate of $20 \mu \mathrm{l} / \mathrm{min}$ in all models, a significant percentage of cells have been deposited. Also, cells with a size of $30 \mu \mathrm{m}$ under all flow rates and viscosities selected for the carrying fluid in this study showed a percentage of sediment.

\section{DISCUSSION}

To evaluate the reliability of the results, a part of those was compared with a similar study by Marin et al., which is presented in Table 2. As can be seen, the results are very close.

As shown in Fig. 5, the two main forces acting on a floating cell are drag $\left(\mathrm{F}_{d}\right)$ and gravitational $\left(\mathrm{F}_{w}\right)$ forces. According to equation 3 , the drag force is a function of viscosity $(\mu)$ and flow rate $(\mathrm{Re})$. Also, the gravitational force relates to the mass and volume of the cell.

Table 2. The number of sediment cells from 300 injected cells at different flow rates for a model with a cell size of $10 \mu \mathrm{m}$ and a media viscosity of 0.001 Pa.s in this study and similar work in the literature.

\begin{tabular}{ccc}
\hline Flow Rate $(\mu / / \mathrm{min})$ & Marin el al. [31] & Current work \\
\hline 20 & 300 & 300 \\
50 & 264 & 263 \\
90 & 166 & 166 \\
180 & 78 & 78 \\
\hline
\end{tabular}

As seen in Fig. 5, drag and ground forces are perpendicular to each other. Therefore, the sum of the two forces is to be predicted to be angled and downward.

According to the result, it can be understood that the trajectory and fate of the cells within the microchannel from the inlet to the outlet more than anything depends on the flow velocity. In all models with a flow rate of $20 \mu \mathrm{l} /$ min, a significant percentage of cell sediment was observed. Cell size is another highly influential factor in cell movement behaviour through a microchannel following the flow rate. For example, in all models of this study, most of the

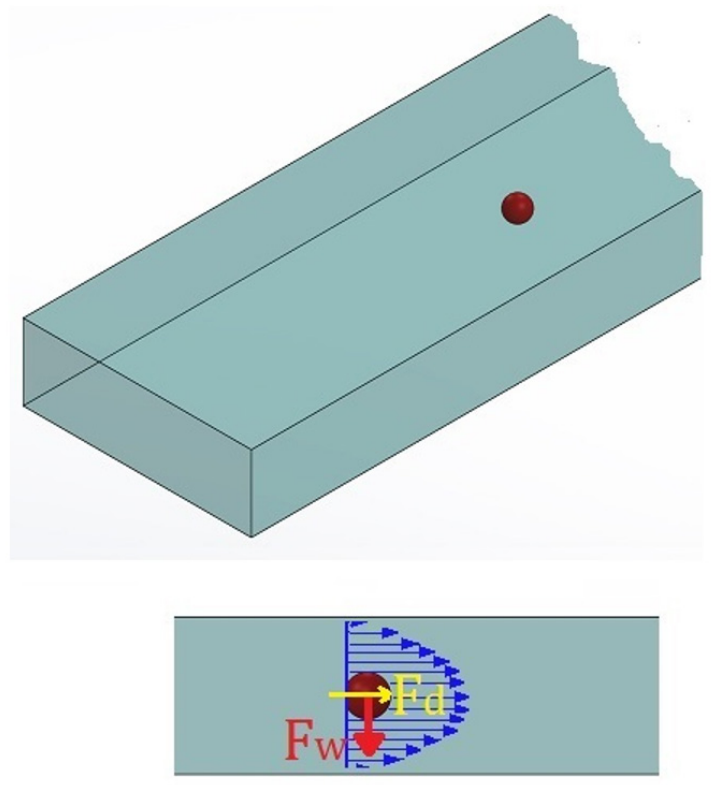

Figure 5. Effective forces on a buoyant cell. 
injected cells with $30 \mu \mathrm{m}$ size could not reach the outlet and got stuck in the microchannel. Moreover, the viscosity of the carrier fluid also plays a vital role in the number of trapped cells. With increasing viscosity in all models, more cells reached the microchannel outlet. The movement of cells towards the outlet without deposition depends on the balance between the two main forces, namely the drag force and the gravitational force. Naturally, when the size of the cells increases due to the difference in density with the solution, it experiences more gravitational force and is pulled down. Similarly, when the flow rate or viscosity of the culture media increases, the drag force on a cell increases and can overcome the gravitational force. We can conclude that fewer cells can trap within transport microchannels in dynamic cell culture with increasing flow rate and viscosity. However, an increased viscosity and flow rate can lead to a higher wall shear stress in the destination scaffold surfaces. Therefore, we may need to be careful about increasing the fluid viscosity and the flow rate. Also, the use of cells of the same size can facilitate the regulation and selection of cell culture conditions such as flow rate and viscosity of the media because the presence of cells with various sizes can make it more difficult to control their trajectory. Therefore, having the same size cells can be considered a prerequisite for a successful cell culture process. Other factors such as microchannel material can affect the fluid flow profile and consequently the fate of cells. For example, since PDMS is a hydrophobic material whereas glass is hydrophilic [42], the velocity profile can vary for each of them, and this cause different streamline modality within a microchannel. In this study, the boundary condition of walls was chosen as no-slip, so the microchannel material effect on cells fate is ignored. Since cell subsidence and, consequently, blockage of a micro-device is a catastrophe, solutions such as sheath fluid flow [43], applying dielectrophoresis [44], an increase in wall shear stress to separate cells from microchannel wall [45] can be considered to overcome this phenomenon.

\section{CONCLUSION}

In this study, the movement of stem cells thought of a microchannel was investigated using discrete phase model CFD analysis. Based on the results of this study, the following conclusions can be drawn:

- All three factors, cell size, flow rate and fluid viscosity, play a decisive role in the movement of cells from the inlet to the outlet of a microchannel.

- The presence of three independent parameters makes the regulation and control of the cell culture process difficult and a challenge that can be managed using computer simulations to solve possible problems.
- Having cells of the same size can be an essential step in reducing the challenges of regulating cell culture conditions.

- The results of this study are limited to a microchannel with specific dimensions. In contrast, the microchannel dimensions can play an essential role in fluid flow and, consequently, cell fate. Hence, new and more studies with different size and geometries of the microchannel are necessary.

\section{CONFLICT OF INTEREST}

The author declare no conflicts of interest.

\section{References}

1. Wiriyasart, S., C. Hommalee, and P. Naphon, Thermal cooling enhancement of dual processors computer with thermoelectric air cooler module. Case Studies in Thermal Engineering, 2019. 14: p. 100445

2. Jayamohan, H., et al., Chapter 11 - Advances in Microfluidics and Lab-on-a-Chip Technologies, in Molecular Diagnostics (Third Edition), G.P. Patrinos, Editor. 2017, Academic Press. p. 197-217.

3. Andrade, J.R., E. Kussul, and T. Baydyk, Microchannel filter for air purification. Open Physics, 2020. 18: p. 241 - 254.

4. Abdollahi, A., et al., Fluid flow and heat transfer of nanofluids in microchannel heat sink with V-type inlet/outlet arrangement. Alexandria Engineering Journal, 2017. 56(1): p. 161-170.

5. Narayanamurthy, V., et al., Microfluidic hydrodynamic trapping for single cell analysis: mechanisms, methods and applications. Analytical Methods, 2017. 9(25): p. 3751-3772.

6. David J. Beebe, a. Glennys A. Mensing, and G.M. Walker, Physics and Applications of Microfluidics in Biology. Annual Review of Biomedical Engineering, 2002. 4(1): p. 261-286.

7. Moghadas, H., et al., Challenge in particle delivery to cells in a microfluidic device. Drug delivery and translational research, 2018. 8(3): p. $830-842$.

8. Morini, G.L., Single-phase convective heat transfer in microchannels: a review of experimental results. International Journal of Thermal Sciences, 2004. 43(7): p. 631-651.

9. Hetsroni, G., et al., Fluid flow in micro-channels. International Journal of Heat and Mass Transfer, 2005. 48(10): p. 1982-1998.

10. Jin, Y., et al., Scale and size effects on fluid flow through self-affine rough fractures. International Journal of Heat and Mass Transfer, 2017. 105: p. 443-451.

11. Cui, J. and Y.Y. Cui, Effects of Surface Wettability and Roughness on the Heat Transfer Performance of Fluid Flowing through Microchannels. Energies, 2015. 8(6): p. 5704-5724.

12. Dai, B.M., M.X. Li, and Y.T. Ma, Effect of surface roughness on liquid friction and transition characteristics in micro- and minichannels. Applied Thermal Engineering, 2014. 67(1-2): p. 283-293.

13. Wyma, A., et al., Non-Newtonian rheology in suspension cell cultures significantly impacts bioreactor shear stress quantification. Biotechnology and Bioengineering, 2018. 115(8): p. 2101-2113.

14. Li, X., et al., In Vitro Recapitulation of Functional Microvessels for the Study of Endothelial Shear Response, Nitric Oxide and [Ca2+]i. PLOS ONE, 2015. 10(5): p. e0126797.

15. Tehranirokh, M., et al., Microfluidic devices for cell cultivation and proliferation. Biomicrofluidics, 2013. 7(5): p. 051502.

16. Lesman, A., Y. Blinder, and S. Levenberg, Modeling of flowinduced shear stress applied on 3D cellular scaffolds: Implications 
for vascular tissue engineering. Biotechnology and Bioengineering, 2010. 105(3): p. 645-654.

17. Ali, D., et al., Permeability and fluid flow-induced wall shear stress in bone scaffolds with TPMS and lattice architectures: A CFD analysis. European Journal of Mechanics-B/Fluids, 2020. 79: p. 376385.

18. Huber, D., et al., Hydrodynamics in Cell Studies. Chemical reviews, 2018. 118(4): p. 2042-2079.

19. Shelby, J.P., et al., A microfluidic model for single-cell capillary obstruction by $<$ em $>$ Plasmodium falciparum $<$ /em $>$-infected erythrocytes. Proceedings of the National Academy of Sciences, 2003. 100(25): p. 14618-14622.

20. Korin, N., et al., Design of well and groove microchannel bioreactors for cell culture. Biotechnology and Bioengineering, 2009. 102(4): p. 1222-1230

21. Coluccio, M.L., et al., Microfluidic platforms for cell cultures and investigations. Microelectronic Engineering, 2019. 208: p. 14-28.

22. Marimuthu, M. and S. Kim, Continuous oxygen supply in pumpless micro-bioreactor based on microfluidics. BioChip Journal, 2015. 9(1): p. 1-9.

23. Byun, C.K., et al., Pumps for microfluidic cell culture. Electrophoresis, 2014. 35(2-3): p. 245-57.

24. Kendall, K. and A.D. Roberts, van der Waals forces influencing adhesion of cells. Philosophical Transactions of the Royal Society B: Biological Sciences, 2015. 370(1661): p. 20140078.

25. Bao, F., et al., Numerical Study of Nanoparticle Deposition in a Gaseous Microchannel under the Influence of Various Forces. 2021 12(1).

26. Liu, Z., et al., Cell Seeding Process Experiment and Simulation on Three-Dimensional Polyhedron and Cross-Link Design Scaffolds. Frontiers in Bioengineering and Biotechnology, 2020. 8(104).

27. Olivares, A.L. and D. Lacroix, Simulation of Cell Seeding Within a Three-Dimensional Porous Scaffold: A Fluid-Particle Analysis. Tissue Engineering Part C-Methods, 2012. 18(8): p. 624-631.

28. Robu, A., A. Neagu, and L. Stoicu-Tivadar, Cell seeding of tissue engineering scaffolds studied by Monte Carlo simulations. Stud Health Technol Inform, 2011. 169: p. 882-6.

29. Campos Marin, A. and D. Lacroix, Computational Simulation of Cell Seeding in a Tissue Engineering Scaffold, in Multiscale Mechanobiology in Tissue Engineering, D. Lacroix, et al., Editors. 2019, Springer Singapore: Singapore. p. 81-104.

30. Lee, H., et al., Computational fluid dynamics for enhanced tracheal bioreactor design and long-segment graft recellularization. Scientific Reports, 2021. 11(1): p. 1187.

31. Marin, A.C., et al., $\mu$-Particle tracking velocimetry and computational fluid dynamics study of cell seeding within a $3 \mathrm{D}$ porous scaffold. Journal of the Mechanical Behavior of Biomedical Materials, 2017. 75(Supplement C): p. 463-469.

32. Ali, D., Effect of scaffold architecture on cell seeding efficiency: A discrete phase model CFD analysis. Computers in biology and medicine, 2019. 109: p. 62-69.

33. Natu, R. and R. Martinez-Duarte, Numerical Model of Streaming DEP for Stem Cell Sorting. Micromachines, 2016. 7(12): p. 217.

34. Sun, J., et al. Size-based hydrodynamic rare tumor cell separation in curved microfluidic channels. Biomicrofluidics, 2013. 7, 11802 DOI: $10.1063 / 1.4774311$

35. Cámara-Torres, M., et al., Improving cell distribution on 3D additive manufactured scaffolds through engineered seeding media density and viscosity. Acta Biomaterialia, 2020. 101: p. 183-195.

36. Ge, J., et al., The size of mesenchymal stem cells is a significant cause of vascular obstructions and stroke. Stem Cell Rev Rep, 2014. 10(2): p. 295-303.

37. Vossenberg, P., et al., Darcian permeability constant as indicator for shear stresses in regular scaffold systems for tissue engineering. Biomechanics and Modeling in Mechanobiology, 2009. 8(6): p. 499.

38. Xue, X., et al., Analysis of fluid separation in microfluidic T-channels. Applied Mathematical Modelling, 2012. 36(2): p. 743755

39. Ali, D. and S. Sen, Computational fluid dynamics study of the effects of surface roughness on permeability and fluid flow-induced wall shear stress in scaffolds. Annals of biomedical engineering, 2018. 46(12): p. 2023-2035

40. Morsi, S.A. and A.J. Alexander, An investigation of particle trajectories in two-phase flow systems. Journal of Fluid Mechanics, 2006. 55(2): p. 193-208.

41. Morsi, S.A. and A.J. Alexander, An investigation of particle trajectories in two-phase flow systems. Journal of Fluid Mechanics, 1972. 55(2): p. 193-208.

42. Del Giudice, F., et al., Particle alignment in a viscoelastic liquid flowing in a square-shaped microchannel. Lab on a Chip, 2013. 13(21): p. 4263-4271.

43. Yun, H., K. Kim, and W.G. Lee, Effect of a dual inlet channel on cell loading in microfluidics. Biomicrofluidics, 2014. 8(6): p. 066501066501.

44. Kang, D.-H., K. Kim, and Y.-J. Kim, An anti-clogging method for improving the performance and lifespan of blood plasma separation devices in real-time and continuous microfluidic systems. Scientific Reports, 2018. 8(1): p. 17015.

45. Couzon, C., A. Duperray, and C. Verdier, Critical stresses for cancer cell detachment in microchannels. Eur Biophys J, 2009. 38(8): p. 1035-47. 